\title{
UN CICLO DE MEJORA EN EL AULA SOBRE LAS CAUSAS DEL DESEMPLEO EN ESPAÑA CON ALUMNOS DE ADMINISTRACIÓN DE EMPRESAS
}

\author{
A CYCLE OF IMPROVEMENT \\ IN CLASSROOM ABOUT THE \\ CAUSES OF UNEMPLOYMENT \\ IN SPAIN WITH STUDENTS OF \\ BUSINESS ADMINISTRATION
}

JOSÉ FERNÁNDEZ-SERRANO

Universidad de Sevilla

Dpto. Economía Aplicada I

jfserrano@us.es

Fecha de recepción: 01-06-2019.

Fecha de aceptación: 11-06-2019.

DOI: http://dx.doi.org/10.12795/9788447221912.056 Pp.: 1283-1307 


\section{Resumen}

El desempleo, en particular el desempleo juvenil, es uno de los problemas estructurales de la economía española con mayor impacto negativo en la sociedad. De ahí la importancia de conocer cuáles son sus características, sus causas y, sobre todo, sus posibles soluciones. Para ello, se necesita un enfoque multidisciplinar y transversal que permita comprender de manera global la enorme complejidad de este problema. Desde esta premisa, se ha elaborado un ciclo de mejora en el aula (CIMA) para alumnos de tercero del Grado de Administración y Dirección de Empresas de la Universidad de Sevilla, que pretende analizar el paro conectando los diversos elementos del mercado laboral, población y tejido empresarial, más allá de la simple enumeración de causas inconexas que suelen plantear los manuales de Economía.

Palabras claves: Administración de empresas, docencia universitaria, experimentación docente universitaria, desempleo y sus causas, economía española.

\section{Abstract}

Unemployment, particularly youth unemployment, is one of the structural problems of the Spanish economy with the greatest negative impact on society. Hence the importance of knowing its characteristics, its causes and, above all, its possible solutions. To this end, a multidisciplinary and transversal framework is needed that allows a global understanding of the enormous complexity of this problem. In this way, an Improvement Cycle In Classroom (ICIC) has been drawn up for students of Business Administration and Management at the University of Seville which aims to analyse unemployment by connecting the different elements of the labour market, population and the business sector, beyond the simple enumeration of unrelated causes which tend to be found in manuals of Economics.

Keywords: Business Administration, college teaching, college teaching experimentation, causes of unemployment, Spanish economy, 


\section{El contexto}

La asignatura sobre la que se aplicó el ciclo de mejora en el aula (CIMA) es Economía Mundial y Española II (EME-II a partir de ahora). Se imparte en la Facultad de CC. Económicas y Empresariales, en 30 del Grado en Administración y Dirección de Empresas. Es una asignatura obligatoria, continuación de EME-I, de 2o- por lo que se "supone" que hay conceptos que el alumno domina; nada más lejos de la realidad: conceptos básicos como la tasa de paro o el PIB continúan siendo grandes desconocidos para muchos de ellos. Como se recoge en el programa, existen dos modelos de evaluación a) la final, donde la calificación se obtiene del examen oficial de toda la materia, y b) la continua, donde el $50 \%$ de la calificación procede de actividades realizadas en clase y el otro $50 \%$ de un test final. De 64 alumnos, 51 eligieron esta última, de manera que sabían que tenían que trabajar en clase. El aula tiene todos los inconvenientes para "innovar": ancha y profunda, con filas de seis asientos y donde falla el proyector y el sonido.

Jornadas de Formación e Innovación Docente del Profesorado | № 2 (2019) Esta obra se distribuye con la licencia Creative Commons 


\section{Diseño del CIMA}

\section{Mapa de contenido}

Este CIMA pretende experimentar en el aula analizando uno de los principales problemas económicos que tiene España: el desempleo. Se trata de un tema de interés para estos alumnos universitarios que el año que viene se incorporarán al mercado laboral.

Uno de los primeros instrumentos desarrollados ha sido el mapa de contenidos con objeto de organizar la materia a impartir (Martín-Salinas et al., 2015). El mapa permite detectar y seleccionar la información principal, así como conceptualizar los contenidos fundamentales, delimitando la organización, estructura e interrelaciones entre ellos (Díaz y Hernández, 1999; De Alba et al., 2017). El mapa propuesto (véase Figura 1) sitúa al desempleo en el centro de los contenidos a estudiar. A continuación, se analizan las principales variables del mercado laboral (activos, parados, ocupados, etc.), así como una serie de conceptos claves (segmentación, temporalidad, etc.). Delimitados los componentes, se analizan las causas del paro considerando tres grupos de factores vinculados entre sí: (a) el factor humano, (b) la calidad del tejido empresarial y (c) el marco institucional. Conocidas las características y las causas, se finaliza con el análisis de las soluciones propuestas, es decir, con las políticas activas y pasivas. Hay que destacar que este "camino" descrito no es único. La interrelación de los elementos permite el recorrido del mapa desde cualquier nudo, puesto que las relaciones entre ellos son multidireccionales y recíprocas. 


\section{JOSÉ FERNÁNDEZ-SERRANO}

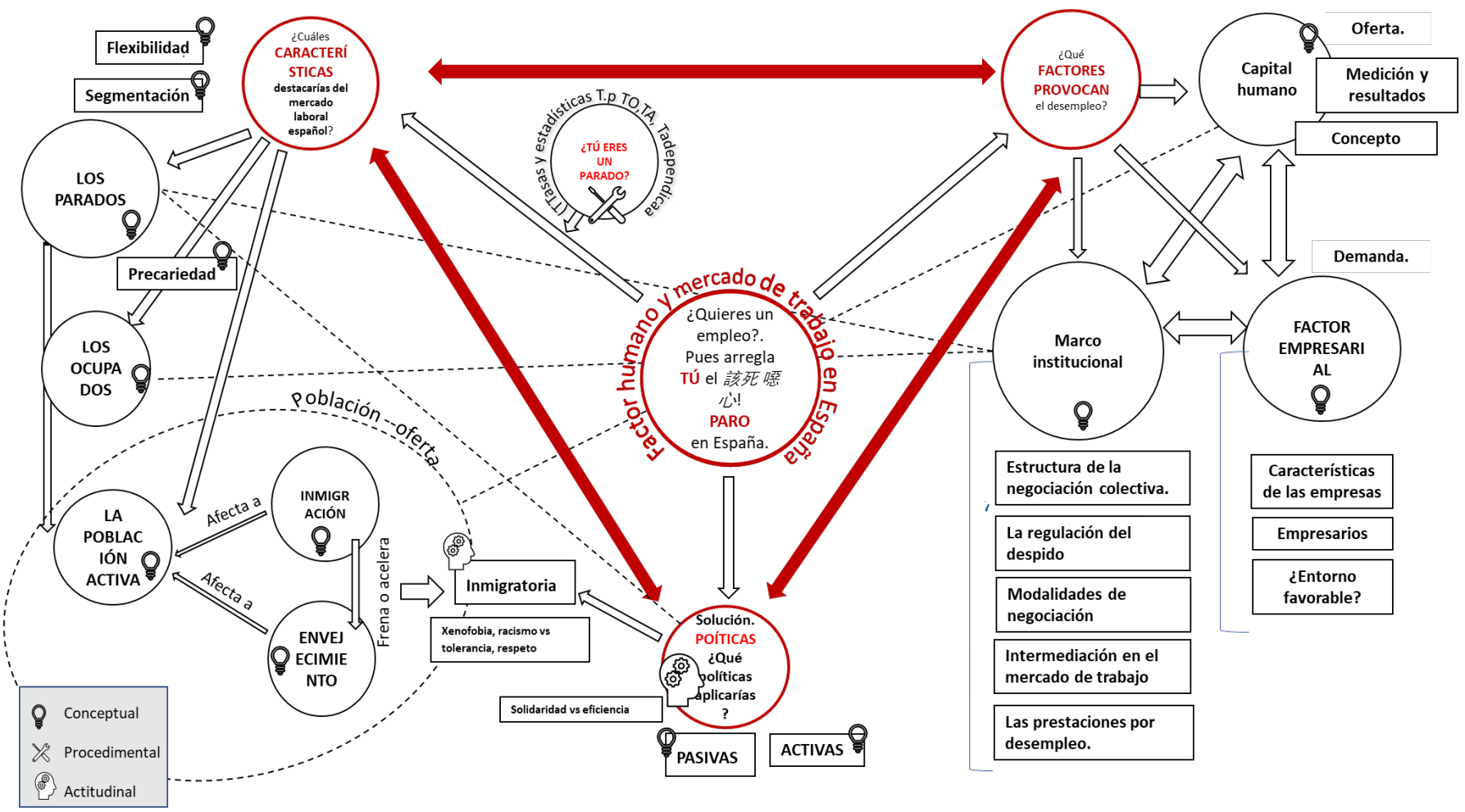

Figura 1. Mapa de contenidos

Jornadas de Formación e Innovación Docente del Profesorado | № 2 (2019) 
El mapa tiene en cuenta la distinción tradicional entre los contenidos propuesta por Coll (1990): contenidos conceptuales, procedimentales y actitudinales. La mayoría del contenido del CIMA es conceptual, si bien, se plantea el uso de las estadísticas del Instituto Nacional de Estadística (INE) para incluir contenido procedimental. En este sentido, el objetivo es que el alumno configure por su cuenta las diversas tasas del mercado laboral, realizando los cálculos necesarios a partir de las cifras suministradas por el INE, hasta llegar a dominar su elaboración y significado; en otras palabras, que aprenda el contenido realizando las acciones que lo conforman (Zabala, 2000). Asimismo, las cuestiones relativas a la inmigración y a las medidas de política son clasificadas como actitudinales por su mayor carga de valores sociales. Como se expone más adelante, a partir del mapa se ha elaborado una serie de actividades que cubren los principales nudos presentes en el mismo.

\section{Modelo metodológico y secuencia de actividades}

El modelo metodológico posible (García Pérez y Porlán, 2017) está pensado para una sesión total de 240 minutos, repartidos en dos clases por semana. En este modelo (Figura 2), se parte del planteamiento de un problema/contexto concreto que debe conocer el alumnado. Se hacen preguntas enunciadas de manera personal, abriendo el debate entre los alumnos. A continuación, se realiza una evaluación de los conocimientos previos, procediendo a una retroalimentación de conceptos claves y/o de aquellos con mayores dificultades. Le sigue una fase de elaboración de contenidos, donde el alumno realiza trabajo tanto personal como colectivo. A lo largo de este proceso, siempre que sea necesario se recibe el apoyo y acompañamiento del profesor. El modelo se cierra con conclusiones generales elaboradas por los alumnos y el profesor, abriéndose nuevos (y futuros) debates e ideas con la intención de motivar al alumno para que profundice en la materia. 


\section{JOSÉ FERNÁNDEZ-SERRANO}

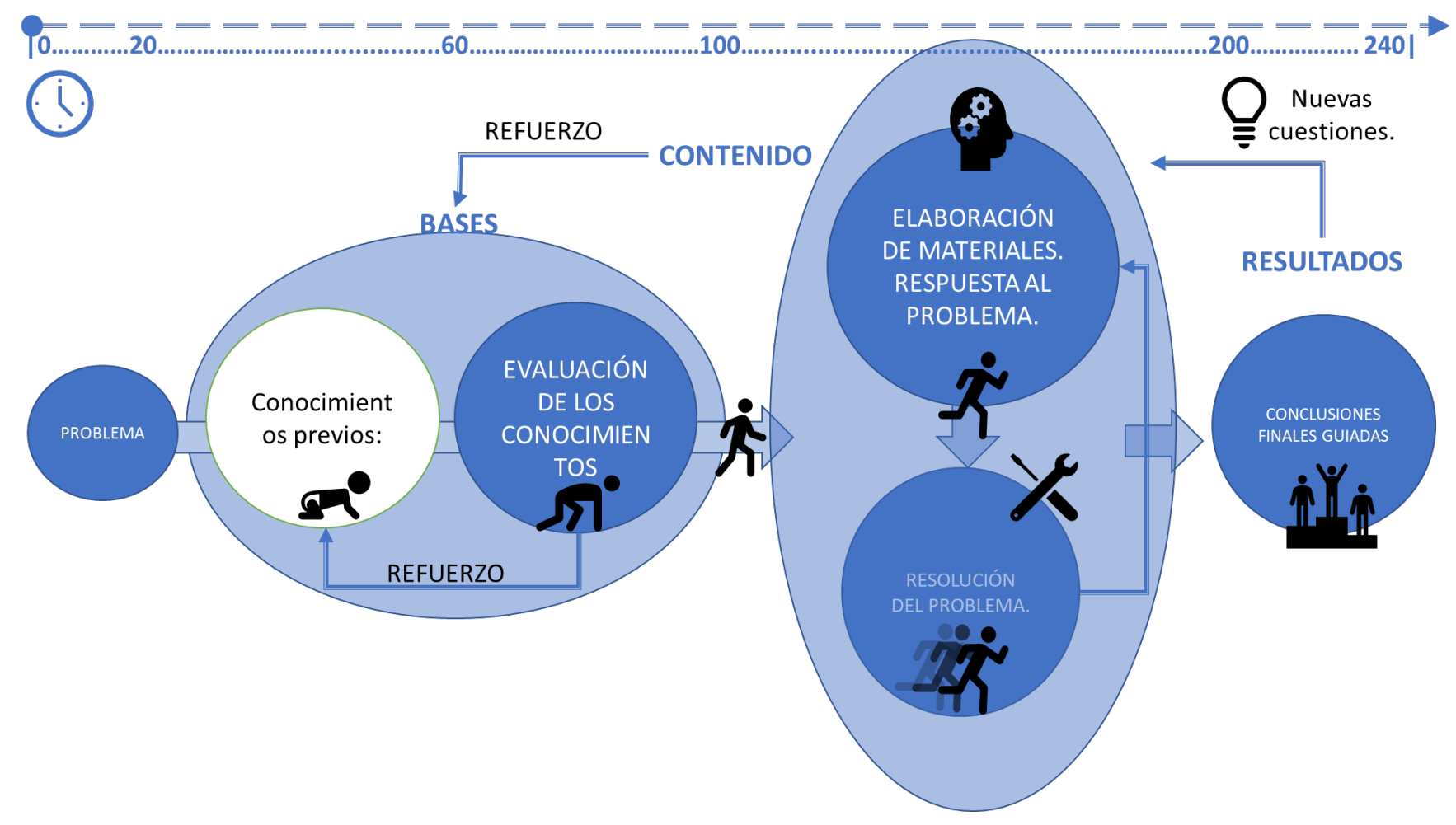

Figura 2. Modelo metodológico.

Jornadas de Formación e Innovación Docente del Profesorado | № 2 (2019) 
La Tabla 1 resume la secuencia de actividades realizadas en este CIMA. Las tareas han sido desarrolladas pensando en el tipo de contenido que se quiere transmitir (Tobón et al., 2010).

Tabla 1. Secuencia de actividades

\begin{tabular}{|c|c|c|}
\hline Descripción de la actividad & Finalidad & Contenido \\
\hline \multicolumn{3}{|c|}{ Sesión 1} \\
\hline \multicolumn{3}{|c|}{1 ¿Por qué crees que tienes que saber...? 10 min. } \\
\hline $\begin{array}{l}\text { 1.1. Cuestiones/contexto. ¿Cuál } \\
\text { es el problema económico } \\
\text { más grave que tiene España?. } \\
\text { ¿Tienes expectativas de } \\
\text { encontrar trabajo el año que } \\
\text { viene?. ¿Conoces a alguien que } \\
\text { sufra las consecuencias del } \\
\text { paro?. ¿Por qué los Gobiernos } \\
\text { no consiguen solucionar el } \\
\text { paro?. ( } 2-3 \text { min.) } \\
\text { 1.2. Debate (5-10 min.). }\end{array}$ & $\begin{array}{l}\text { Toma de } \\
\text { conciencia: es un } \\
\text { problema cercano } \\
\text { y grave que les } \\
\text { afecta. Captar } \\
\text { el interés del } \\
\text { alumno. } \\
\text { Expresión oral y } \\
\text { defensa de ideas. }\end{array}$ & $\begin{array}{l}\text { Presentar el } \\
\text { problema del } \\
\text { paro. Los jóvenes } \\
\text { son uno de los } \\
\text { colectivos que } \\
\text { más lo sufren. } \\
\text { El daño social y } \\
\text { económico. Paro } \\
\text { estructural vs } \\
\text { coyuntural. }\end{array}$ \\
\hline \multicolumn{3}{|l|}{2 ¡Sigue tú!.10 min. } \\
\hline $\begin{array}{l}\text { 2.2. Debate y puesta en común } \\
\text { de ideas sobre el video ( } 5 \text { min.) }\end{array}$ & $\begin{array}{l}\text { Emitir juicios } \\
\text { de valor, } \\
\text { pensamiento } \\
\text { crítico. Opinar } \\
\text { razonadamente. } \\
\text { Analizar } \\
\text { información }\end{array}$ & $\begin{array}{l}\text { Evaluación crítica } \\
\text { de la situación } \\
\text { del mercado } \\
\text { de trabajo: } \\
\text { ¿las ayudas } \\
\text { desincentivan la } \\
\text { búsqueda?. }\end{array}$ \\
\hline \multicolumn{3}{|c|}{ 3. "Tú ya lo sabes....o lo mismo no". 45-50 min. } \\
\hline $\begin{array}{l}\text { Cuestionario inicial (El becari@ } \\
\text { del Ministerio). }\end{array}$ & $\begin{array}{l}\text { Evaluar los } \\
\text { conocimientos } \\
\text { previos. }\end{array}$ & $\begin{array}{l}\text { Indicadores del } \\
\text { mercado laboral y } \\
\text { casusas del paro. } \\
\text { Capital humano. }\end{array}$ \\
\hline
\end{tabular}

Jornadas de Formación e Innovación Docente del Profesorado | № 2 (2019) Esta obra se distribuye con la licencia Creative Commons Reconocimiento-NoComercial-SinObraDerivada Internacional (CC BY-NC-ND 4.0.) 


\begin{tabular}{|c|c|c|}
\hline $\begin{array}{l}\text { 4.1. Se proyecta un video ( } 6.22 \\
\text { min.) Mondrágon-Universidad. } \\
\text { 4.2. Debate sobre el video ( } 10 \\
\text { min.) }\end{array}$ & $\begin{array}{l}\text { Emitir juicios } \\
\text { de valor, } \\
\text { pensamiento } \\
\text { crítico. Analizar } \\
\text { información. }\end{array}$ & $\begin{array}{l}\text { Especialización } \\
\text { sectorial y paro. } \\
\text { Sobrecualificación } \\
\text { vs “ni-ni". }\end{array}$ \\
\hline \multicolumn{3}{|l|}{$\begin{array}{l}\text { 4.3 Trabajo para casa. Se } \\
\text { explica la ficha de trabajo } 1 \\
\text { (tasas y evolución del mercado } \\
\text { laboral) a responder en la } \\
\text { siguiente sesión. (3-5 min.). }\end{array}$} \\
\hline \multicolumn{3}{|l|}{$\begin{array}{l}\text { 4.4. Se presenta otro material } \\
\text { audiovisual de interés ( } 3-5 \\
\text { min.). }\end{array}$} \\
\hline \multicolumn{3}{|c|}{ Sesión 2} \\
\hline \multicolumn{3}{|c|}{ 6. Cierre primera actividad $45+45=90 \mathrm{~min}$. } \\
\hline $\begin{array}{l}\text { 6.1. Elaboración de materiales. } \\
\text { Por grupos de } 6 \text { tienen que } \\
\text { presentar una única propuesta } \\
\text { de las cuestiones planteadas } \\
\text { en la ficha } 1 \text { (máx. } 45 \text { min.). } \\
\text { 6.2. Conclusiones. El portavoz } \\
\text { del grupo expone las } \\
\text { conclusiones. Solución de } \\
\text { consenso (máximo } 45 \text { min.). }\end{array}$ & $\begin{array}{l}\text { Trabajo grupal: } \\
\text { organización y } \\
\text { reparto de tareas } \\
\text { y consenso. } \\
\text { Expresión oral, } \\
\text { fomentar el } \\
\text { debate y el } \\
\text { pensamiento } \\
\text { crítico. }\end{array}$ & $\begin{array}{l}\text { Principales } \\
\text { variables del } \\
\text { mercado laboral } \\
\text { y su evolución. } \\
\text { Características de } \\
\text { los parados y de } \\
\text { los ocupados. }\end{array}$ \\
\hline \multicolumn{3}{|l|}{ 7. Tienes que seguir....10 min. } \\
\hline \multicolumn{3}{|l|}{$\begin{array}{l}\text { Se presenta la ficha } 2 \text { (causas } \\
\text { del paro). }\end{array}$} \\
\hline \multicolumn{3}{|c|}{ Sesión 3} \\
\hline \multicolumn{3}{|c|}{ 8. "Volvemos a empezar" (5-10 min.). } \\
\hline $\begin{array}{l}\text { 8.1. Breve presentación ( } 2 \text { min.). } \\
\text { 8.2. Aclaración de dudas y } \\
\text { conceptos claves de la clase } \\
\text { anterior (si es necesario, máx.10 } \\
\text { min.). }\end{array}$ & $\begin{array}{l}\text { Aclaración de } \\
\text { conceptos claves. } \\
\text { Que "hablen entre } \\
\text { ellos" y fomentar } \\
\text { el debate. } \\
\text { Evaluar los } \\
\text { conocimientos. }\end{array}$ & $\begin{array}{l}\text { Repasamos las } \\
\text { tasas, evolución } \\
\text { y características } \\
\text { de las principales } \\
\text { variables del } \\
\text { mercado laboral. }\end{array}$ \\
\hline
\end{tabular}

Jornadas de Formación e Innovación Docente del Profesorado | № 2 (2019) Esta obra se distribuye con la licencia Creative Commons Reconocimiento-NoComercial-SinObraDerivada Internacional (CC BY-NC-ND 4.0.) 
9.1. Los alumnos se sientan por grupos para dar respuesta a la ficha 2. Cada grupo trabaja en una de las causas del paro (máx. 50 min.). Cada grupo expondrá las principales conclusiones de su trabajo. El profesor interviene si es necesario (máx. 45 min.).

9.3. Desenlace. Se llega a una solución de consenso en la clase (máx.10-15 min.).
Trabajo en grupo.

Elaboración de gráficos y tasas.

Expresión escrita.
Causas del paro: el emprendedor y su entorno, capital humano, factores institucionales y demográficos.

Causas del paro: el emprendedor y su entorno, capital humano, factores institucionales del mercado laboral, factores demográficos.

Causas del paro. Visión de la problemática del paro en conjunto.

10. "Ya vamos acabando..."

Trabajo para casa: ficha 3

(inmigración) (máx. 5 min.)

Expresión oral,

fomentar el

debate y el

pensamiento

crítico.

\begin{tabular}{|c|c|c|}
\hline \multicolumn{3}{|c|}{ Sesión 4} \\
\hline \multicolumn{3}{|l|}{ 11. "...ahí vamos otra vez" (35 min.). } \\
\hline $\begin{array}{l}\text { 11.1 Breve presentación/repaso. } \\
\text { 11.2. Cerramos la inmigración. } \\
\text { Test Kahoot de la ficha } 3 \text { de } \\
\text { trabajo. Conclusiones generales } \\
\text { y aclaración de dudas. } \\
\text { 11.3. Debate: ¿el inmigrante } \\
\text { quita puestos de trabajo? (10- } \\
15 \text { min.) }\end{array}$ & $\begin{array}{l}\text { Evaluar los } \\
\text { distintos niveles. } \\
\text { Opinión razonada. } \\
\text { Fomentar la } \\
\text { tolerancia y el } \\
\text { respeto. }\end{array}$ & $\begin{array}{l}\text { Inmigración y su } \\
\text { impacto en el } \\
\text { mercado laboral. }\end{array}$ \\
\hline \multicolumn{3}{|l|}{ 12. No es país para viejos. } \\
\hline $\begin{array}{l}\text { Exposición oral de un grupo } \\
\text { de sobre el proceso de } \\
\text { envejecimiento (máx. } 35 \text { min.). }\end{array}$ & $\begin{array}{l}\text { Expresión oral } \\
\text { y razonamiento } \\
\text { crítico. }\end{array}$ & $\begin{array}{l}\text { Proceso de } \\
\text { envejecimiento } \\
\text { e impacto en la } \\
\text { economía. }\end{array}$ \\
\hline
\end{tabular}




\begin{tabular}{|c|c|c|}
\hline $\begin{array}{l}\text { Presentación de la ficha } 4 \\
\text { sobre las políticas de empleo. }\end{array}$ & & \\
\hline \multicolumn{3}{|c|}{ Sesión 5} \\
\hline \multicolumn{3}{|c|}{ 14. Con la política hemos topado (Máximo 75 min.) } \\
\hline $\begin{array}{l}\text { 14.1. Se trabaja la ficha } 4 \text {. Cada } \\
\text { grupo defiende medidas de } \\
\text { política pasivas y activas de las } \\
\text { principales fuerzas políticas. } \\
\text { Tienen } 10 \text { min. para una puesta } \\
\text { en común dentro del grupo y } 5 \\
\text { min. para exponer. }\end{array}$ & $\begin{array}{l}\text { Búsqueda de } \\
\text { información, } \\
\text { juicio crítico, } \\
\text { expresión oral. } \\
\text { Trabajo en grupo. }\end{array}$ & $\begin{array}{l}\text { Políticas de } \\
\text { empleo. }\end{array}$ \\
\hline $\begin{array}{l}14.2 \text { Cierre de la actividad: } \\
\text { solución de consenso por parte } \\
\text { de la clase (máx. } 20 \text { min.). }\end{array}$ & $\begin{array}{l}\text { Expresión oral, } \\
\text { fomentar el } \\
\text { debate y el } \\
\text { pensamiento } \\
\text { crítico. }\end{array}$ & \\
\hline \multicolumn{3}{|l|}{ 15. Todo tiene un fin (20-25 min.). } \\
\hline $\begin{array}{l}\text { Test final ( } 20 \text { preguntas) sobre } \\
\text { el contenido de la materia ( } 20 \\
\text { min.). }\end{array}$ & $\begin{array}{l}\text { Evaluar los } \\
\text { distintos niveles } \\
\text { de los alumnos. }\end{array}$ & $\begin{array}{l}\text { Contenido } \\
\text { completo de la } \\
\text { materia impartida. }\end{array}$ \\
\hline \multicolumn{3}{|c|}{ Sesión 6} \\
\hline $\begin{array}{l}\text { Cuestionario final (El becari@ } \\
\text { del Ministerio). }\end{array}$ & $\begin{array}{l}\text { Evaluación de lo } \\
\text { aprendido. }\end{array}$ & \\
\hline
\end{tabular}

\section{El cuestionario inicial}

Para lograr mejorar el proceso de enseñanza-aprendizaje se ha experimentado en este CIMA con una evaluación inicial del alumnado. Un diseño correcto de la evaluación del nivel del alumno ofrece información valiosa para dirigir el trabajo que se va a realizar en clase hacia el objetivo propuesto (Arrien et al., 2016). Entre las diversas herramientas disponibles, se optó por emplear un cuestionario. En este sentido, Martí y $\operatorname{Orgaz}(2011,2014)$ comentan las bondades de este instrumento para una aproximación más real al nivel de conocimientos del alumno. El cuestionario 
inicial (Tabla 2) se ha realizado como un pequeño caso para que los alumnos se sientan representados en una situación "cotidiana", donde los protagonistas sean ellos mismos. Se trata de experimentar en el aula mediante el planteamiento de un problema cercano, empleando lenguaje coloquial y alejado de la dialéctica de la materia que permita un aprendizaje más continuo y duradero (Barrows, 1986; Días y Hernández, 1999; Prieto, 2006)

Tabla 2. El becari@del Ministerio (cuestionario)

Enhorabuena, estás de suerte, Espana te necesita: eres el becari@de turno en el Ministerio de trabajo, migraciones y seguridad social. Tu jefa, la excelentísima Sra. Magdalena valerio (sí, la misma, a la que llevas el café, porque otra cosa no has hecho) te ha pedido esta mañana que le ayudes a elaborar un discurso que va a realizar en París sobre la situación del mercado laboral (¡Oh, la, la,! habrá cena de picoteo). Tienes que quedar bien, por supuesto, pero iiihorror!!! internet no funciona (¿Google?, iiNooo!!). Sudores fríos caen por tu frente. "El nuev@, que entre", se oye gritar a la señora detrás de la puerta. Tragas saliva mientras te tocas el cordón rociero que escondes debajo de la chaqueta protocolaria. Entras al despacho mientras piensas en todo el tiempo que has perdido mirando el WhatsApp en vez de atender a ese "profe" tan bien peinado de EME2...¿cómo se llamaba?. Comienza el espectáculo: Alea iacta est.

1.- "Hola, internet no funciona, supongo que te habrás dado cuenta. Necesito que me calcules los indicadores clave del mercado laboral francés...jah!, y explícamelos que yo estudié en la Rey Juan Carlos". Te suelta una página rota del diario Le Monde que lees deprisa y mal, algo habitual en ti, pero que te permite saber que la población total (en millones) es de: 60 , de los cuales 8 tienen menos de 16 años, que están ocupados unos 40 y que tan solo 5 están desempleados. ¿Qué información sobre el mercado de laboral 
lle darías con esos datos si quieres seguir manteniendo tu magnífico trabajo no remunerado en el Ministerio? Recuerda que se lo tendrás que explicar. Y si "te atascas" di en qué y porqué, lo mismo se apiada de ti. (15 min.+2 de lectura).

2.- Sigue la tortura, te van a salir llagas en los dedos de tanto frotar el cordón rociero: "Virgencita ayúdame". "¿Qué?, ya has terminado. Bueno, espero que estos datos sean correctos, si no, ya sabes lo que te espera. Por cierto, acabo de hablar con el jefe del INE y de la Seguridad Social. Uno me ha dicho que el paro en España pasó de, aproximadamente, el 25 por ciento en 2014 a menos del 15 por ciento en 2019, sin embargo, el otro me ha dicho que el número de afiliados a la seguridad social ha disminuido. iiA la calle van a ir los dos!!. Me están liando. Pásame el teléfono que se van a enterar". Rápido, como le explicarías que puede que no sea un error y que los dos pueden estar en lo cierto (5 min.+2 de lectura).

3.-“¡Olé mi niñ@!. Como se nota que has estudiado en la Universidad de Sevilla y no en la "Pablo de Ovejide". (Ovejide.....jiva nuclear te tiraba en lo alto). ¿Sabes?, he hablado con don Amancio y me ha contado algo sobre los activos de capital de su empresa, la Zara esa, y que se la han valorado en 14837 millones de euros, casi nada. Lo voy a decir a mi discurso, dice que es la joya de la corona española. Por cierto, lo mismo algún día te pago algo, ¿en cuánto te valoras tú?". Espera, ¿te acaba de preguntar qué cuánto vales?, ¿qué en cuánto te valoras?. Te está saliendo sangre en las yemas de los dedos de tanto cordón....espera, esta te la sabes, tú no eres menos que "la Zara". Explícaselo: ¿cuánto vales tú?, ¿en cuánto te valoras? Justificale la respuesta (5 min.+ 2 lectura).

4.-"Buena respuesta, si señor, se nota que has estudiado. Otra cosa, seguro que los franceses me preguntan algo sobre la inmigración. Siempre me preguntan que cuál es mil 
ppinión sobre que los inmigrantes quiten el trabajo a los españoles y nunca sé que responder, ¿qué les digo?". Vamos, que queda poco, ayuda a la pobre mujer y no olvides justificar tu respuesta ( 5 min. + 2 de lectura).

5.- "Lo tendré en cuenta. Me caes bien, lo mismo te invito a una reunión con mis asesores del Ministerio. ¿Sabes?, no se ponen de acuerdo sobre cuáles son las casusas del paro, que si esto, que si lo otro. Lo mismo un día también los despido a todos". Aprovecha y lúcete, esa sangre que cae a borbotones por tus dedos no puede ser derramada en vano. Aclararé las causas del paro del país que te vio nacer (5 min. + 2 de lectura).

- Habrás mantenido tu puesto de trabajo o habrás hundido en la miseria la reputación del reino español? Pronto lo sabrás.

\section{Aplicación del CIMA}

\section{Diario de sesiones}

En la primera sesión, a pesar de mis esfuerzos, los alumnos estaban apáticos, sin mostrar una participación activa. En la siguiente hora tenían un examen parcial de otra asignatura. La herramienta que cambió esa dinámica pasiva y aburrida de la clase fue el cuestionario inicial. El cuestionario les rompió los esquemas: surgían dudas, interés e inquietudes; les chocaba la manera de preguntarles “icuánto valen ellos?"; ni se lo habían planteado. Fue un acierto plantear las preguntas alejadas de la terminología tradicional de la materia y empleando el humor. Después de su recogida, vimos un video sobre el modelo productivo del grupo empresarial Mondragón. Este vídeo también fue un gran acierto aumentando su interés. Se quedaron con ganas de más. 
La segunda sesión se desarrolló sin muchos problemas. Los alumnos habían trabajado en casa y entregado la actividad por la plataforma web. Soy reacio a mandar "deberes para casa", y tenía muchas dudas por la posible objeción del alumnado; sin embargo, considero que la respuesta ha sido satisfactoria. Por grupos, empiezan a trabajar y, a pesar de las limitaciones del espacio físico, la actividad se desarrolla sin problemas y me permito "quitarme del centro de la clase" (Finkel, 2008) y dejarles a ellos que elaboren sus propios contenidos. Me voy paseando por los grupos, incluso me siento con algunos de ellos para resolver dudas. Esa cercanía no les molesta ni les incomoda.

En la sesión 3, tras responder a un par de dudas, reparto la actividad programada y los pongo a trabajar por grupos. Decidí facilitarles el contenido de la materia en papel, aunque lo tenían en la web y algunos iban con portátiles, con vistas a facilitar el trabajo en equipo. Me vuelvo a quitar del medio de la clase y les dejo trabajar: me callo la boca (Finkel, 2008). Sin embargo, observo que no todos los alumnos se involucran por igual con la actividad. Los animo, pero no tienen ganas de trabajar o hacen lo mínimo. En este tipo de actividad, creo que es conveniente para que todos los alumnos se impliquen en el trabajo del grupo -cuando el grupo es numeroso- es llevar a cabo una evaluación explícita basada en una tabla de puntuaciones (Rivero y Porlán, 2017).

En la sesión 4, tuvo lugar el debate sobre las políticas de empleo (estaban próximas las elecciones generales y pude aprovechar la coyuntura). Esta actividad fue un éxito rotundo: los alumnos disfrutaron desmontando las propuestas realizadas por sus compañeros. De nuevo, parece evidente que funcionan muy bien contenidos de actualidad, cotidianos para el alumno, que permiten que expresen sus ideas y opiniones al respecto, siendo el profesor un mero coordinador/moderador que las dota de rigor 
académico cuando es necesario. Una clase muy divertida y amena con contenido actual.

En la sesión 5 retomo una actividad sobre inmigración que quedó pendiente por falta de tiempo. Les di unos minutos para que la leyesen en silencio y luego hicimos una lectura colectiva. Abrí el debate seleccionando a un par de alumnos y realizando cuestiones directas que debían responder. En esta ocasión, varios alumnos mostraban una falta de interés y respondían simplemente, "no lo sé" o "no lo tengo claro". De nuevo, creo que una puntuación explícita de la actividad donde se valore un esfuerzo e interés en la materia resultaría un aliciente para involucrar a este tipo los alumnos, tienen que ser conscientes de que están elaborando contenidos con sus respuestas y opiniones.

Finalmente, después de una semana de vacaciones, realicé el cuestionario final. Quería saber si, después de una semana sin tocar la materia, habían "retenido" algo. El análisis de los resultados son objeto de otra experimentación en el CIMA a través del análisis de escaleras de aprendizaje (Rivero y Porlán, 2017).

\section{Escaleras de aprendizaje}

Aunque solo se ha podido realizar la comparación con 18 cuestionarios, en términos generales, se han obtenido resultados satisfactorios en todas las preguntas planteadas en el cuestionario. 
Tabla 3. Escaleras de aprendizaje

\begin{tabular}{|c|c|c|c|c|c|c|c|}
\hline \multicolumn{4}{|c|}{ Cuestión 1. Tasas e indicadores. } & \multicolumn{4}{|c|}{ Cuestión 3. Capital humano. } \\
\hline \multicolumn{2}{|c|}{ Final } & & $11 \%$ & Final & & $22,2 \%$ & \\
\hline & & $28 \%$ & $1 \%$ & & & $55,6 \%$ & $0,0 \%$ \\
\hline & $56 \%$ & $17 \%$ & & & $11,1 \%$ & $44,4 \%$ & \\
\hline $6 \%$ & $33 \%$ & & & $11,1 \%$ & $27,8 \%$ & & \\
\hline $50 \%$ & & \multicolumn{2}{|c|}{ Inicial } & $27,8 \%$ & & \multicolumn{2}{|l|}{ Inicial } \\
\hline \multicolumn{4}{|c|}{$\begin{array}{l}\text { Nivel 1: No responde/blanco. No es } \\
\text { capaz de segmentar la población. } \\
\text { Nivel 2: No separa la población total } \\
\text { de la población mayor de } 16 \text { años. } \\
\text { No contempla la población activa. } \\
\text { Nivel 3: Separa la población activa } \\
\text { de la población mayor de } 16 \text { años. } \\
\text { Calcula alguna tasa. } \\
\text { Nivel 4: Segmentación precisa de la } \\
\text { población. Plantea y calcula las tres } \\
\text { tasas. }\end{array}$} & \multicolumn{4}{|c|}{$\begin{array}{l}\text { Nivel 1: No responde/blanco. o } \\
\text { barbaridades y/o ocurrencias. } \\
\text { Nivel 2: Plantea una solución } \\
\text { basada en el salario que le } \\
\text { correspondería. } \\
\text { Nivel 3: Intuye el papel de la } \\
\text { productividad como determinante } \\
\text { del salario, pero no establece } \\
\text { las causas ni el origen de dicha } \\
\text { productividad. } \\
\text { Nivel 4: Plantea el papel de la } \\
\text { formación y la experiencia como } \\
\text { determinantes del capital humano } \\
\text { y, por tanto, de los determinantes } \\
\text { de su productividad. Salario } \\
\text { como resultado de los niveles de } \\
\text { productividad }\end{array}$} \\
\hline
\end{tabular}

En este sentido, la Tabla 3 recoge las escaleras para dos preguntas que son representativas de la evolución seguida por el conjunto de alumnos. Además de los porcentajes, se incluye la descripción de los niveles propuestos. 


\title{
Evaluación del CIMA
}

\author{
Respecto al modelo docente y \\ el mapa de contenidos
}

Las herramientas desarrolladas con el CIMA han dotado a mi práctica habitual de una mayor coherencia a partir de una secuencia que he respetado en todas mis clases. $\mathrm{Ha}$ sido un acierto partir del planteamiento de un problema/ contexto concreto y cercano a los alumnos, empleando preguntas enunciadas de manera personal que les involucren en la materia (Barrow 1986; Bain, 2005; Prieto, 2006). También debo destacar la evaluación previa del nivel del alumnado. Esta evaluación, mediante un test o cuestionario, ha sido una herramienta tremendamente útil, que me ha permitido "afinar" aún más el contenido a impartir y ha permitido una retroalimentación de los contenidos, de una manera casi inmediata que los alumnos valoran positivamente (Balter et al, 2013). En la elaboración de contenidos, mi objetivo era lograr una participación más activa del alumnado que permitiese un aprendizaje duradero. Esa actividad la he desarrollado mediante ejercicios, lecturas, test, debates, preguntas directas, etc. (Rivero y Porlán, 2017). Muchas de ellas se han realizado en horario de clases, pero también desde casa. En este sentido, el trabajo para casa ha sido una agradable sorpresa: aunque se han quejado de los "deberes", más del 80\% de los alumnos entienden que son necesarios, que les ayudan a la comprensión de la materia y, sobre todo, que tienen un propósito. Además, me ha sido fácil impulsar el empleo de las nuevas TICs como una herramienta docente con un propósito claro (Salinas, 2004). La búsqueda activa del alumno a través de internet de ciertos contenidos, el "pique" entre ellos por ver quién lo hace más rápido y las explicaciones a los compañeros de igual a igual (García y García, 2012), dinamizan la clase y les motiva a continuar. 
Para hacer funcionar el nuevo modelo docente era necesario una correcta planificación de la secuencia de actividades acorde con el contenido que quería impartir (Tobón et al., 2010). A pesar de la planificación, no siempre ha sido posible la correcta sincronización de los tiempos de las actividades con los resultados que esperaba obtener, lo cual demuestra la exigencia de este método para los docentes. Pero más allá de la planificación de las actividades, está su propósito, el porqué de esa actividad y no otra. Y ahí es donde he tenido que afrontar un nuevo reto. El reto de "repensar" el contenido de la materia, en extraer los contenidos fundamentales, la jerarquía entre ellos y las relaciones entre los mismos. Para ello, la configuración del mapa de contenidos ha sido uno de los grandes aciertos que me ha ayudado a conseguir las preguntas claves y la secuencia de actividades que quería desarrollar (Novak y Cañas, 2006). En este sentido, he reordenado el contenido de varios temas del programa oficial de la asignatura y he ampliado el tiempo de impartición que, en un principio, estaba previsto para desarrollar esa materia. Era necesario. La jerarquía y la interconexión de los contenidos claves me han resultado mucho más fácil pues una de las características propias de la metodología de mi asignatura es, precisamente, plantear la interrelaciones de casualidad multidireccional y recíproca de los componentes de una estructura económica.

La elaboración del mapa de contenidos me ha permitido tomar consciencia de varios aspectos metodológicos que han mejorado la docencia. En primer lugar, que es posible unir varios contenidos de distintos temas del programa oficial en una sola pregunta/problema inicial, generando un necesario pensamiento transversal, que creo dota de riqueza a la asignatura. La mayoría de los manuales plantean cada tema de manera "estanca", sin apenas permeabilidad e interconexión entre los mismos, 
siendo la interrelación una necesaria mejora para comprender la complejidad de la realidad económica. En segundo lugar, que ese replanteamiento no está exento de problemas y obstáculos, en particular, por el modelo de pensamiento del propio alumno. Hay muchos alumnos que están acostumbrados a una enseñanza más "tradicional" basada en tomar apuntes y "necesitan" un temario estructurado con sus correspondientes epígrafes. Plantear una metodología donde se busca un aprendizaje "más natural", desarrollado por el propio alumno, pero donde se plantean contenidos transversales que proceden de más de un tema del programa, puede provocar que muchos de ellos se sientan "desorientados". Así lo he constatado en mi ciclo de mejora. En este sentido, aunque he llegado a la conclusión de que, en parte, echan de menos esos apuntes bien estructurados que dicta su profesor, el verdadero problema radica en que no le dan un verdadero valor al trabajo que desarrollan ellos mismos. Finalmente, que hay que planificar tareas específicas para contenidos específicos. La separación entre contenido conceptual, procedimental y actitudinal y su correspondiente actividad ha sido uno de los retos más dificiles a los que me he enfrentado en el CIMA. Si bien es cierto que la inmensa mayoría de mi contenido es conceptual, he buscado contenido procedimental y actitudinal, dotando a la materia de una mayor "riqueza" y variedad que el alumno ha valorado favorablemente.

\section{Respecto a la evaluación}

Finalmente, entramos en la evaluación. Por supuesto, es necesario realizar un diagnóstico de las ideas y conocimientos adquiridos por los estudiantes. Valoro de manera muy positiva las enseñanzas obtenidas a partir de la aplicación de las escaleras de aprendizaje, en particular, sobre la necesidad de determinar los grupos y establecer los obstáculos entre escalones (Rivero y Porlán, 2017). Solo 
por plantear esos aspectos ya obliga al docente a reconsiderar su enseñanza. Son unas herramientas muy útiles sobre todo cuando se realizan análisis individuales para localizar a los alumnos con niveles más bajos y ver su evolución. No obstante, el tiempo a dedicar es proporcional al número de alumnos en clase y en ocasiones funcionan mejor test rápidos y directos que fomenten el feed-back inmediato con los alumnos (Balter et al., 2013).

He observado que muchos alumnos siguen pensando en una calificación tradicional de su proceso de aprendizaje y que, no tener una retroalimentación precisa, en forma de nota numérica, rompe sus esquemas a la hora de afrontar la actividad y, por tanto, la asignatura. De hecho, la inmensa mayoría de ellos considera que tenía información para evaluarles y no les hubiera importado que les pusiera una nota numérica a todo ese trabajo que han desarrollado a lo largo del ciclo de mejora. Aunque cerremos actividades y lleguemos al consenso sobre los interrogantes planteados en clase, echan en falta esa calificación numérica pues la consideran un indicador clave sobre "cómo van en la asignatura". De esta manera, después del CIMA, considero que todo trabajo del alumno tiene que tener una valoración y que ésta debe ser conocida por el alumno antes de afrontar la actividad. Estoy de acuerdo con que la motivación intrínseca del estudiante es la ideal para que el modelo de aprendizaje obtenga los mejores resultados en su enseñanza, pero desgraciadamente en muchos casos, es la motivación extrínseca (esa calificación de "9 sobresaliente") la que mueve a muchos alumnos a estudiar. Pasar de un alumno consumidor pasivo de apuntes a uno como productor activo de contenidos debe ser recompensado y así tienen que sentirlo ellos.

Por último, ha sido también útil solicitarles a ellos su opinión sobre el ciclo de mejora y que me valoren a mí como profesor. Me he dado cuenta de la importancia que tiene que esa evaluación se realice con preguntas abiertas 
(Rivero y Porlán, 2017) donde ellos puedan expresar libremente sus ideas, pues permite que el profesor tome consciencia de problemas que él no observa o, simplemente, ni se había planteado.

\section{Principios Didácticos que deben permanecer en el futuro}

A modo de conclusión puedo afirmar que la experimentación realizada a través del CIMA ha reforzado la idea de plantear un modelo metodológico partiendo de una pregunta o problema clave. Problemas cotidianos, cercanos al alumno que supongan una implicación directa para ellos, formulado de manera directa y personal es uno de los pilares básicos para comenzar la secuencia de aprendizaje duradero (Prieto, 2006). En este sentido, resulta relevante emplear un mapa de contenidos donde se organiza y jerarquiza el contenido objeto de estudio. Mi objetivo es ampliarlo a más temas para que, prácticamente, aborde la mayor cantidad de temario posible. Para ello, es fundamental buscar más contenidos procedimentales y actitudinales y diseñar las tareas específicas para ellos, así como planificar la necesaria secuencia de actividades.

Todo ello queda supeditado a una evaluación previa del alumno. Es fundamental conocer el punto de partida del alumno: ayuda al profesor y también a los estudiantes (que sean conscientes de lo que saben y de lo que no). En este sentido, el empleo de un cuestionario inicial (y final) se configura como una herramienta válida (Martí y Orgaz, 2011; Rivero y Porlán, 2017) que, en mi opinión, funciona de manera correcta cuando se evalúa el contenido más global y fundamental de la materia. A partir del mismo, sí que es posible desarrollar escaleras de aprendizajes para el conjunto del alumnado (fuente). Para el contenido secundario, donde el empleo de las escaleras es más engorroso para el profesor con muchos alumnos en clase, es más útil 
un tipo test (Kahoot, en particular) buscando siempre la inmediatez a la hora de responder las dudas a través de las nuevas tecnologías.

Sin duda alguna, este modelo de enseñanza apuesta por un alumnado activo, productor de sus propios contenidos, donde el profesor se quita del medio de la clase siempre que sea posible (Finkel, 2008). Para ello, hay que plantear toda una serie de actividades para casa y para clase donde el trabajo por grupos es fundamental, puesto que fomenta el aprendizaje entre iguales (García y García, 2012). En este sentido, mi experiencia desarrollada en el CIMA me ha mostrado que hay que otorgar una calificación numérica a determinadas actividades para motivar al alumno y que sean conscientes de que se valora su esfuerzo.

Finalmente, ha sido un acierto la valoración final del alumno hacia el profesor. Es fundamental pasar un cuestionario con preguntas abiertas para que expresen sus comentarios sobre la docencia recibida, puesto que permite tomar consciencia de problemas que de otra manera es dificil de detectar. 


\section{Referencias bibliográficas}

Arrien, E., Ubieta, E., Ugarriza, J.R. (2016). La evaluación inicial en las Aulas de Aprendizaje de Tareas. Departamento de Educación, Universidades e investigación. Documentos de apoyo.

Bain, K. (2005). Lo que hacen los mejores profesores universitarios. Valencia: Publicaciones Universidad de Valencia.

Balter, O., Enstrom, E. y Klingenberg, B. (2013). The effect of short formative diagnostic web quizzes with minimal feedback. Computers and Education, 60 (1), 234-242.

Barrows, H.S. (1986). A Taxonomy of problem-based learning methods, Medical Education, 20/6, 481-486.

Coll, C. (1990). Psicología y currículum, Una aproximación psicopedagógica a la elaboración del curriculum escolar. México: Paidós.

De Alba, N., Porlán, R. y Navarro, E. (2017). Los fines y los contenidos de la enseñanza. En Porlán, R. (Coord). Enseñanza universitaria. Cómo mejorarla, pp. 55 -72. Madrid: Morata.

Díaz, F. y Hernández, G. (1999). Estrategias docentes para un aprendizaje significativo. México: McGraw-Hill.

Finkel, D. (2008). Dar clases con la boca cerrada. Valencia: Publicaciones Universidad de Valencia.

García Pérez, F.F. y Porlán, R. (2017). Los principios didácticos y el modelo didáctico personal. En Porlán, R. (Coord). Enseñanza universitaria. Cómo mejorarla, pp. 93-105. Madrid: Morata.

García, J. L. y García, R. (2012). Aprender entre iguales con herramientas web 2.0 y Twitter en la universidad. Análisis de un caso. EDUTEC, Revista Electrónica de Tecnología Educativa, 40, 1-14.

Martí, C.P. y Orgaz, N. (2011). El cuestionario como herramienta de autoevaluación en el proceso de aprendizaje de la asignatura Contabilidad Financiera y Analítica. Revista de Educación en Contabilidad, Finanzas y Administración de Empresas, 11, 51-66.

Martí, C.P. y Orgaz, N. (2014). Análisis del uso de cuestionarios en contabilidad financiera. Educación XX1, 17(1), 271-290.

Martín-Salinas, C., Parro-Moreno, A.I. y Cid-Galán, M.L. (2015). Utilización de mapas conceptuales como innovación docente para el desarrollo de competencias. EducMed, 16(3),173-176. 
Prieto, L. (2006). Aprendizaje activo en el aula universitaria: el caso del aprendizaje basado en problemas. $R e^{-}$ vista de Ciencias Humanas y Sociales, 64(124), 173-196.

Rivero, A. y Porlán, R. (2017). La evaluación en la enseñanza universitaria. En Porlán, R. (Coord). Enseñanza universitaria. Cómo mejorarla, pp.73-92. Madrid: Morata.

Salinas, J. (2004). Innovaciọn docente y uso de las TIC en la enseñanza universitaria. RUSC. Universities and Knowledge Society Journal, 1(1), 1-16

Tobón, S.; Pimienta, J. y García Fraile, J.A. (2010). Secuencias didácticas: aprendizaje y evaluación de competencias. Pearson. México.

Zabala, A. (Coord.) (2000). Cómo trabajar los contendidos procedimentales en el aula. Barcelona: Editorial Graó.

Jornadas de Formación e Innovación Docente del Profesorado | № 2 (2019) Esta obra se distribuye con la licencia Creative Commons 